\section{Organic grains in Taurus interstellar clouds}

WHITTET ET AL. ${ }^{1}$ have reported the detection of an interstellar absorption

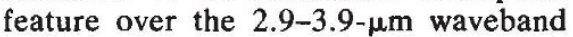
arising from dust grains in the Taurus clouds. The absorption is found to peak at the wavelength $\lambda \simeq 3 \mu \mathrm{m}$, with an extended shoulder on the longwave side of the peak, implying an additional broad absorption band centred on $\lambda \simeq 3.4 \mu \mathrm{m}$. Whilst the absorption at $3 \mu \mathrm{m}$ could be attributed to $\mathrm{OH}$ stretching in $\mathrm{H}_{2} \mathrm{O}$-ice the broad absorption at $3.4 \mu \mathrm{m}$ must arise from $\mathrm{CH}$ stretching in some form of condensed organic material. If $\tau_{3}$ and $\tau_{3.4}$ denote the respective optical depths at the centres of the $3-\mu \mathrm{m}$ and $3.4-\mu \mathrm{m}$ bands, Fig. $3 b$ of ref. 1 gives a ratio

$$
\frac{\tau_{3.4}}{\tau_{3}} \cong \frac{1}{4.8}
$$

for the Taurus material. Now, the mass absorption coefficient of ice at the centre of the $3-\mu \mathrm{m}$ band, from the data of Bertie et al. $^{2}$, is

$$
\kappa_{\text {ice }} \cong 36,000 \quad \mathrm{~cm}^{2} \mathrm{~g}^{-1}
$$

using a specific gravity $s=0.917$ for ice. (For amorphous ice ${ }^{3}$ the same mass absorption coefficient is obtained for a slightly lower value of specific gravity, $s=0.75$.) For organic polymers of a wide range of types, including polyformaldehyde $^{4.5}$ and biomolecules ${ }^{6}$, we find that the absorption coefficient $\kappa_{\text {org }}$ at the centre of a broad 3.4- $\mu \mathrm{m}$ band satisfies the inequality

$$
\kappa_{\text {org }}<1,200 \mathrm{~cm}^{2} \mathrm{~g}^{-1}
$$

Noting that

$$
\frac{\tau_{3.4}}{\tau_{3}}=\frac{\kappa_{\text {org }} \rho_{\text {org }}}{\kappa_{\text {ice }} \rho_{\text {ice }}}
$$

where $\rho_{\text {org }}$ and $\rho_{\text {ice }}$ are the respective mass densities of organic material and of ice, and using equations (1), (2) and (3) we obtain

$$
\frac{\rho_{\text {org }}}{\rho_{\text {ice }}}>6.25
$$

We thus conclude that there is a clear preponderance of condensed organic matter over $\mathrm{H}_{2} \mathrm{O}$-ice in the Taurus dust clouds.

Note added in proof: We are well aware of the references cited in the annexed reply, but consider them irrelevant. Interstellar grains cannot be largely $\mathrm{H}_{2} \mathrm{O}$-ice of radii $0.3 \mu \mathrm{m}$ because then the extinc- tion at $5,000 \AA$ would be comparable to that at the centre of the $3-\mu \mathrm{m}$ band, whereas observationally it is at least an order of magnitude more.

\section{F. HOYLE \\ N. C. WICKRAMASINGHE}

\section{Department of Applied}

Mathematics and Astronomy,

University College,

PO Box 78, Cardiff CF1 $1 X L, U K$

1. Whittet, D. C. B., Bode, M. F., Longmore, A. J., Baines, D. W. T. \& Evans, A. Nature 303, 218 (1983).

2. Bertie, J. E., Labbé, H. J. \& Whalley, E. J. chem. Phys. 50, 4501 (1969).

3. Léger, A., Gauthier, S., Defourneau, D. \& Rouan, D. Astr. Astrophys. 117, 164 (1983)

4. Wickramasinghe, N. C. Nature, 252, 462 (1974).

5. Cooke, A. R thesis, Univ. College, Cardiff (1976).

6. Hoyle, F. Olavesen, A. H. \& Wickramasinghe, N. C. Nature 271, 229 (1978).

7. Hoyle, F., Wickramasinghe, N. C., Al-Mufti, S., Olavesen, A. H. \& Wickramasinghe, D. T. Astrophys. Space Sci. 83, 405 (1982).

WHITTET REPLIES-The conclusion drawn by Hoyle and Wickramasinghe must be treated with caution, as it is based on the assumption that $\mathrm{C}-\mathrm{H}$ bond absorption in organic polymers is the only possible explanation of the long-wavelength 'shoulder' in the 3.1- $\mu \mathrm{m}$ interstellar ice band profile. As pointed out in our paper ${ }^{1}$, several other explanations have been put forward. Leger et $a l^{2}$ have argued that the phenomenon is a scattering effect in large ice grains, and that the entire profile can be matched by $\mathrm{H}_{2} \mathrm{O}$ ice containing a small proportion of $\mathrm{NH}_{3}$. Recent model calculations by Tielens and Hagen ${ }^{3}$ suggest that grain mantles contain $\sim 60 \%$ water-ice. These ${ }^{3.4}$ and other ${ }^{5}$ investigators attribute the shoulder of the ice feature to hydrogen bond interactions between $\mathrm{H}_{2} \mathrm{O}$ and other molecules such as $\mathrm{NH}_{3}, \mathrm{H}_{2} \mathrm{CO}$ and $\mathrm{H}_{2} \mathrm{O}_{2}$ in the icy matrix. There is clearly no need to invoke complex organic molecules to explain this feature; moreover, the case for organic polymers as major grain constituents has been weakened by recent results ${ }^{6}$ concerned with other parts of the spectrum.

Present astronomical data at $3 \mu \mathrm{m}$ are of insufficient spectral resolution to allow firm conclusions to be drawn on the detailed chemistry of interstellar grain mantles. Recent advances in instrumentation offer the prospect of major advances in this field in the near future.

Note added in proof: We have not attempted to explain the total visual extinction in terms of pure ice grains; indeed, our results imply that ice only appears at optical depths $>$ about 5 magnitudes into the cloud. The authors cited above (refs 3 and 4) have demonstrated that a core-mantle grain model in which the mantle, where present, is predominantly water ice, can match the 2.9$4.0 \mu \mathrm{m}$ absorption profile. We have no reason to doubt the integrity of these results.

\section{C. B. WhitTeT}

Division of Physics and Astronomy,

Preston Polytechnic,

Preston PR1 2TQ, UK

1. Whittet, D. C. B., Bode, M. F., Longmore, A. J., Baines, D. W. T. \& Evans, A. Nature 303, 218 (1983)

Leger, A., Gauthier, S., Defourneau, D. \& Rouan, D. Astr. Astrophys. 117, 164 (1983).

3. Tielens, A. G. G. M. \& Hagen, W. Astr. Astrophys. 114, 245 (1982).

4. Hagen, W., Tielens, A. G. G. M. \& Greenberg, J. M. Astr. Astrophys. 117, 132 (1983).

5. Knacke, R. F., McCorkle, S., Peutter, R. C., Erickson, E. F. \& Kratschmer, W. Astrophys, 260, 141 (1982), E. F. \& Kratschmer, W. Astrophys. J. 260, 141 (1982). C. B. Mon. Not. R. astr. So 202, 971 (1983).

\section{ESR studies of planktonic foraminifera}

SATO $^{1}$ has recently reported the possibility of dating foraminifera by, ESR techniques. We wish to comment on three problems relating to this method of dating: first, the signal may be reduced by optical bleaching during laboratory handling; second, the dose contribution due to excess ${ }^{230} \mathrm{Th}$ must be taken into account; third, the signal may be unstable for samples greater than a million years old because of thermal decay, rather than anomalous fading as he suggested.

As part of a project on the ESR and thermoluminescence (TL) properties of foraminifera, we have made a brief study of the effect of light on the TL signals. Although stalagmitic calcite has been reported to be relatively insensitive to light ${ }^{2}$, we are very much aware of the light sensitivity of other materials ${ }^{3}$. We took a portion of foraminifera $>60 \mu \mathrm{m}$ from the top of a deep ocean core, RC14-37 (lat. $01^{\circ} 28^{\prime} \mathrm{N}$, long. $90^{\circ} 10^{\prime} \mathrm{E}$ ) and gave it a $\gamma$ dose of $600 \mathrm{~Gy}$ ( $60 \mathrm{krad})$. Subsamples were then placed $7 \mathrm{~cm}$ from a $40 \mathrm{~W}$ tungsten lamp for $15 \mathrm{~h}$ and others placed $35 \mathrm{~cm}$ from a $300 \mathrm{~W}$ mercury sunlamp for $7.5 \mathrm{~h}$. The samples lost respectively $78 \pm 2$ and $95 \pm 2 \%$ of the signal from the $275^{\circ} \mathrm{C}$ TL peak. Since the electron traps responsible for the ESR signal are thought to be the same as those giving rise to the $275^{\circ} \mathrm{C}$ TL peak ${ }^{4}$, we think that experiments should be carried out to determine whether the ESR signal is similarly affected by light. If so, appropriate precautions should then be taken when handling samples to be used for dating. It is, of course, possible that the loss of TL signal could be due to a reduction of the number of active luminescence centres, in which case no loss of ESR signal would be seen. 